\title{
AVALIAÇÃO DA COMPETITIVIDADE TURÍSTICA DO TERRITÓRIO
}

\author{
FABIO POLLICE ${ }^{1}$ \\ Rosario De IUlio ${ }^{2}$
}

\begin{abstract}
Resumo - À escala local o turismo sustentável requer o desenvolvimento de uma configuração atractiva, coerente com o quadro dos recursos territoriais e com as expectativas do mercado, capaz de interpretar em termos dinâmicos e inovadores as formas evolutivas da procura, baseando-se nas especificidades territoriais. A análise dos recursos locais adquire assim um papel estratégico, no âmbito da definição das políticas do turismo, fornecendo aos actores locais um enquadramento competitivo, indispensável para a realização de escolhas estratégicas e a antevisão das trajectórias de desenvolvimento do território. O texto visa propor uma metodologia de avaliação da competitividade turística do território, que leva à distinção da melhor posição estratégica, entendida como uma configuração turístico-atractiva, que permite ao território exprimir na totalidade as suas próprias potencialidades sem renegar, por um lado, a dimensão de identidade (coerência territorial) e, por outro, as condições específicas do mercado turístico (coerência do mercado). Para ser eficaz, o planeamento turístico deve apoiar-se num modelo de análise da competitividade, que permita ler e interpretar as vocações territoriais, tornando-as indicações prescritivas para a acção política.
\end{abstract}

Palavras-chave: Recursos, atractividade turística, vocação turística, competitividade.

\begin{abstract}
AsSESSING THE TOURISTIC COMPETITIVENESS OF THE PORTUGUESE TERRITORY. On a local scale, sustainable tourism entails the development of an attractive pattern consistent with the framework of territorial resources and market expectations. Such a pattern should therefore be adaptive to any changes in the demand in new and dynamic terms, appealing to the territorial features of the local context. Hence, the analysis of territorial resources comes to play a key role in the development of tourism policies, providing local stakeholders with the competitive skills necessary to make their own strategic choices and to plan territorial development paths. The paper proposes a method for assessing the touristic competitiveness
\end{abstract}

Recebido: Agosto, 2010 Aceite: Novembro, 2010.

1 Professor Catedrático de Geografia, Facoltà di Lettere, Università degli Studi del Salento Lecce, Itália. E-mail: fabio.pollice@unisalento.it

2 Professor de Geografia economico-politica, Facoltà di Scienze Organizzative e Gestionali e professor de Marketing Facoltà di Lingue e Letterature Straniere Moderne Università degli Studi della Tuscia - Viterbo, Itália. Doutoramento em Geografia, Faculdade de Letras, Universidade de Lisboa E-mail: rodeiulio@virgilio.it 
of an area with the aim of identifying the more appropriate strategic positioning, meant as a tourist-attractive configuration. This could allow the area itself to express its full potential without rejecting, on the one hand, its identity and vocation (spatial coherence) and, on the other hand, the specific requirements of the touristic market (market consistency). In order to be effective, tourism planning must be based on a model of analysis of competitiveness which should be able to understand and interpret the territorial vocations, transposing them into indications of prescriptive nature for political acting.

Key words: Competitive resources, tourist attraction, tourist vocation, competitive placement, competitiveness.

Résumé - EVALUer La COMPÉTITIVITÉ TOURISTIQUe D'Un TERRITOIRE. Le tourisme durable demande, à l'échelle locale, le développement d'une configuration attrayante qui soit cohérente avec le cadre des ressources du territoire et avec les attentes du marché, c'est-à-dire qui soit capable d'interpréter en termes dynamiques et novateurs les tendances évolutives de la demande, tout en se basant sur les spécificités du territoire et du contexte local. L'analyse des ressources territoriales acquiert ainsi un rôle stratégique dans le domaine de la définition des politiques du tourisme, en fournissant aux acteurs locaux un encadrement compétitif, indispensable à la réalisation de choix stratégiques et à la prévision des trajectoires du développement du territoire. Cette contribution vise à proposer une méthodologie d'évaluation de la compétitivité touristique d'un territoire qui conduit à la distinction du positionnement stratégique le plus opportun, considérée comme une configuration touristique attractive, et qui puisse permettre au territoire d'exprimer pleinement son propre potentiel, sans pour cela renier, d'un côté sa propre dimension d'identité et sa vocation (cohérence territoriale), et de l'autre, les conditions spécifiques du marché touristique (cohérence du marché). Pour être efficace, la planification touristique doit en effet être fondée sur un modèle d'analyse des compétitivités qui soit à même de lire et d'interpréter les vocations territoriales, en les traduisant en indications de nature prescriptive pour l'action politique.

Mots clés: Ressources compétitives, attrait touristique, vocation touristique, emplacement compétitif, compétitivité.

\section{INTRODUÇÃO: AS ASPIRAÇÕES TURÍSTICAS DO TERRITÓRIO}

O nível de atractividade ${ }^{3}$ de um destino turístico deriva de um conjunto complexo e articulado de factores tangíveis e intangíveis, habitualmente caracterizados por um elevado nível de interdependência e de reciprocidade; raramente essas relações são pouco intensas,

3 Define-se como a capacidade de um território para atrair determinados fluxos (de homens de negócios, de turistas, de capitais financeiros, de iniciativas empresariais) um complexo conjunto de factores (materiais e imateriais) que o qualificam e o distinguem do espaço geográfico (nacional, regional ou global) onde tais fluxos têm origem. A atractividade, todavia, não depende só das condições territoriais específicas, mas sobretudo da interação sinérgica entre eles e a forma como tais condições são percebidas fora do contexto territorial (a imagem). Trata-se de um conceito relacional e dinâmico, que tende a assumir diferente valor com o passar do tempo e a variação do espaço, mudando portanto em razão das características do fluxo considerado e do período histórico. A atractividade turística é derivada da atractividade territorial, mas as duas podem não coincidir. Por isso, os operadores públicos e privados do sector turístico, para adequar a novas condições do mercado, tentam ao mesmo tempo preservar a identidade territorial e a integridade ambiental, tal como é definido nos princípios do desenvolvimento sustentável (Pollice Spagnuolo, 2009a). 
sobretudo quando queremos avaliar um território em termos prospectivos, ou seja, quando pretendemos compreender a sua capacidade de activar um fluxo de procura turística, do ponto de vista da sua potencialidade. Além disso, quando estas potencialidades são escassas, irrelevantes ou inadequadas para atrair fluxos significativos de procura, podem surgir condições de atractividade como proveito "artificial", fruto de investimentos económicos segmentados, como é o caso de algumas localidades que têm concentrado a sua própria aposta turística na realização de grandes parques temáticos. Esta reflexão, apesar de ser inatacável no plano teórico, pode causar perigosas distorções no plano político; por exemplo, pode justificar as aspirações turísticas dos territórios, quando estas localidades não conseguem exprimir também, em termos prospectivos, uma capacidade atractiva específica, ou quando estas aspirações se revelam não sustentáveis por razões económicas ou ambientais. O turismo, tanto numa economia pós-industrial, normalmente caracterizada por processos de transformação, depois de uma fase de crise do nível do emprego, como numa economia fraca e marginal, ainda a procurar a sua própria via para o desenvolvimento, é frequentemente identificado como um sector estratégico, factor de crescimento e motor de desenvolvimento, envolvendo recursos públicos ou privados. Esta atitude em relação ao turismo origina factores que podem ser assim resumidos:

i) aparece como um sector relativamente pouco complexo e que pode ser desenvolvido mesmo em lugares que não têm tradições ou capacidades específicas;

ii) para os empresários privados, as barreiras económico-administrativas de entrada no mercado são mais baixas do que em qualquer outro sector económico, aumentando tudo isto a atractividade e o interesse social;

iii) cria um sentido de gratificação na comunidade local, porque se refere às especificidades do território, com que a comunidade se identifica;

iv) no âmbito do debate político sobre os objectivos do desenvolvimento turístico observa-se normalmente um baixo nível de discussão surgindo, às vezes, o turismo enfatizado nos programas políticos, para aumentar a concordância com as escolhas do governo.

Estes factores aumentam as aspirações turísticas de localidades sem vocação turística ${ }^{4}$, criando no imaginário colectivo uma visão deformada da realidade e do seu potencial atractivo, a fim de dirigir as escolhas de investimentos de capitais públicos e privados em direcção a um modelo de desenvolvimento que o território não consegue "suportar". Tudo isto obriga e dirige a aç̧ão política para uma visão onde, posteriormente, se vão basear os processos de planificação territorial (Minca, 1996; Burns, 2004; Berardi, 2007; Dredge, Jekins, 2007). Nestes casos, as aspirações turísticas são não só baseadas na análise objectiva das vocações do território, mas produzem uma mistificação da realidade territorial e das referidas vocações. Desta maneira, o turismo apresenta-se como um factor de desterritorialização, capaz de

4 É um aspecto particular da vocação do território. Esta última pode ser explicada como a aptidão de um território para assumir uma configuração económico-produtiva predefinida, quando ela está em coerência com o conjunto dos recursos materiais e imateriais do território disponíveis (coerência territorial) e com as condições do contexto global (coerência identitária) que constitui a subjectividade territorial. A esta última é atribuída a tarefa de interpretar e realizar as vocações territoriais. A vocação turística, pelo contrário, é caracterizada por condições subordinadas que não podem prescindir umas das outras, influenciando-se mutuamente (Caroli, 2006). 
comprometer as qualidades atractivas do território e de o expor à acção especulativa, de matriz endógena ou exógena. Pelo contrário, a referência às vocações territoriais - como se sublinhará - permite dirigir as escolhas individuais ou colectivas, incluindo-as num quadro de coerência territorial que garante a sustentabilidade económica e ambiental no projecto de desenvolvimento local.

$\mathrm{Na}$ realidade, a pergunta a fazer não é tanto sobre o tipo de configuração turística que se deseja assumir mas, sim, sobre a configuração turístico-atractiva ${ }^{5}$ que o território é capaz de exprimir, em função das suas próprias vocações turísticas, das oportunidades oferecidas num cenário competitivo: as características estruturais e as tendências evolutivas da procura, por um lado, e as orientações competitivas para a concorrência (destinos concorrentes), por outro.

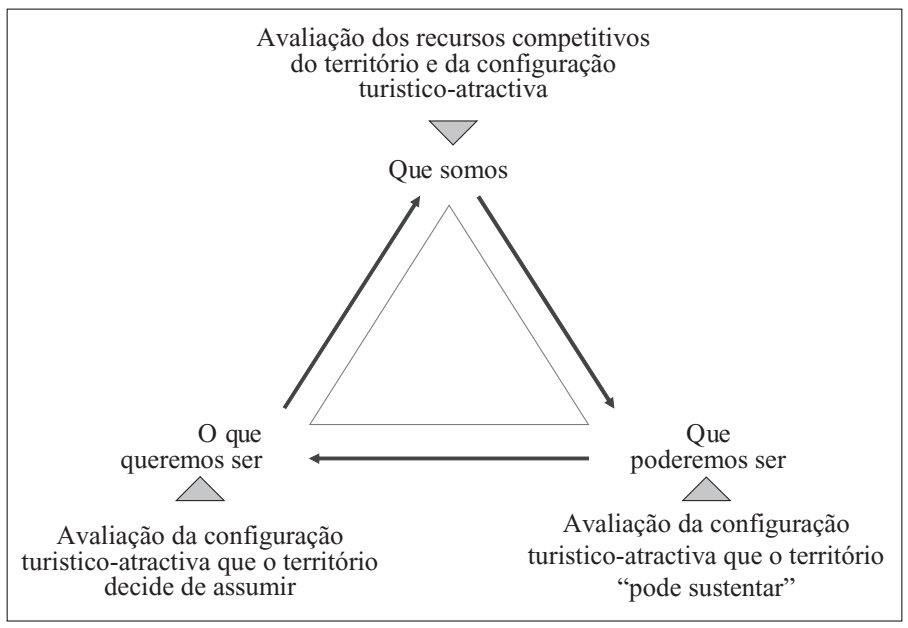

Fig. 1 - O processo de definição da configuração turístico-atractiva. Fig. 1 - The process of defining an attractive tourism configuration.

Na mesma base é preciso avaliar como pode o turismo contribuir para o desenvolvimento do território. De notar que nos casos em que as aspirações turísticas se vão basear numa forte vocação territorial, é a análise desta última que deve dirigir as escolhas dos actores locais e, não, as aspirações da comunidade local ou dos políticos. Isto quer dizer que não são irrelevantes as aspirações turísticas do território - ou melhor, estas representam uma fase essencial na construção da identidade turística dos locais e no envolvimento dos actores locais e da comunidade, na sua totalidade - mas a prioridade deve ser atribuída à fase de análi-

5 Entende-se como a orientação atractiva do sistema turístico local aquela que deriva da dotação de recursos territoriais (factores de atractividade), e do sistema de fruição, que com base neles foi construído. A orientação atractiva de facto, responde aos objectivos de adequação da atractividade do território à procura dos fluxos turísticos actuais e em perspectiva. Tudo isto demonstra que a configuração turístico-atractiva é estrategicamente coerente se reflecte as necessidades dos fluxos turísticos que se quer atrair. 
se das vocações territoriais e, mais especificamente, à avaliação dos recursos territoriais para a competitividade turística ${ }^{6}$. É preciso considerar que, relativamente às vocações territoriais, estas tendem a diminuir os comportamentos emuladores que determinam a dilatação da oferta e têm por referência modelos de matriz exógena, quase sempre caracterizados por um baixo nível de sustentabilidade (Hall, 2007; Enrigth Newton, 2004; Bahalis, 2000).

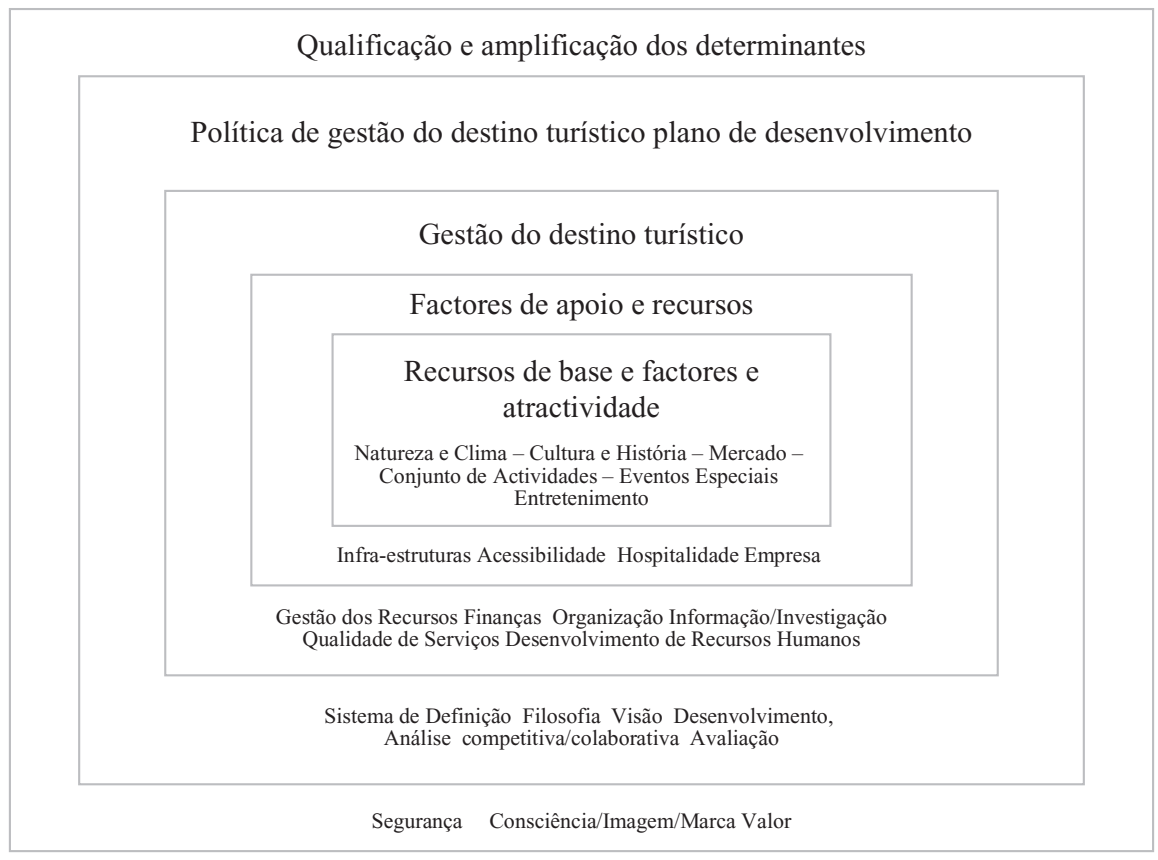

Fig. 2 - As determinantes da competitividade turística de um destino. Fig. 2 - Factors determining the competitiveness of a touristic destination.

Fonte: Adapdato de Crouch e Ritchie, 1999

\section{AVALIAÇÃO DA VOCAÇÃO TURÍSTICA A PARTIR DOS RECURSOS COMPETITIVOS}

Nos últimos dez anos, a concorrência no mercado turístico aumentou significativamente, em consequência da entrada de novos competidores, mais agressivos e organizados, e das mudanças da procura e da intermediação da oferta. A competição deslocou-se gradualmente

6 A competitividade de um destino turístico é a capacidade para satisfazer de forma mais eficaz e eficiente (eficiência económica e ambiental) as necessidades dos fluxos turísticos, preservando as próprias qualidades territoriais e contribuindo para melhorar o bem-estar actual e em perspectiva da comunidade local. O conceito de competitividade turística reporta-se ao de competitividade territorial, mas apresenta uma especificação sectorial que se insere numa relação de interdependência e de complementaridade com a territorial (Dall'Ara, 2006; Franch, 2010). 
da esfera dos negócios para a esfera territorial, obrigando a considerar a atractividade turística do território como um factor crítico do sucesso das estratégias competitivas dos sistemas locais de oferta turística. A atractividade surge assim como um pressuposto territorial para activar uma oferta turística, mas também como produto colectivo, que deriva da interacção dinâmica e sistémica entre os actores locais que, directa ou indirectamente, participam na mesma cadeia do valor; é esta interacção que permite obter condições atractivas do contexto territorial, produzindo um conjunto de benefícios económicos, sociais, culturais e ambientais. O valor acrescentado que se determina para melhorar os níveis de atractividade e de fruição do território turístico não pode ser medido em termos económicos, nem por referência às categorias específicas dos sujeitos, mas deve ser avaliado em termos globais, tendo por referência toda a comunidade que vive naquele contexto. A atractividade adquire um valor instrumental na realização dos objectivos de desenvolvimento sustentável, invertendo uma interpretação subserviente das lógicas de lucro, expressão de algumas categorias de sujeitos que, não raramente, pertencem a outros contexos territoriais e se movem com lógicas especulativas.

Trata-se de um produto sistémico no qual coexistem, integrando-se mutuamente, relações verticais de utilização para fins turísticos do património ambiental e cultural e relações horizontais que, ao contrário, permitem integrar os factores atractivos, para responder com maior eficácia às solicitações do mercado. Se a atractividade é um produto colectivo, não circunscrito ao limitado campo dos operadores turísticos (onde contribui também a comunidade local com os próprios comportamentos), qualquer intervenção de mudança tem de ter por referência um modelo partilhado de governança, que assegure o envolvimento activo de todos os actores locais e que permita obter uma eficaz coordenação do projecto individual ou colectivo.

Para compreender, na sua totalidade, a inovação desta diferente aproximação à atractividade, será adequado preceder este raciocínio de uma análise mais cuidadosa do próprio conceito de atractividade e do valor explicativo que assume em relação aos fenómenos turísticos.

A atractividade de um destino turístico depende da interrelação de diferentes qualidades territoriais, tangíveis e intangíveis, e não tanto da sua posição em relação às áreas de irradiação turística, aos fluxos circulatórios e às áreas mais próximas. Na avaliação do potencial atractivo do território é preciso considerar também os recursos (culturais, naturais, de paisagem $)^{7}$ que ficam na sua proximidade geográfica e possam ser incluídos nos itinerários dos turistas que o visitam. Estes estão tão associados aos recursos tangíveis,como os atractivos do lugar (Ejarque, 2003).

O sistema turístico receptor que compreende o conjunto dos serviços oferecidos aos visitantes, corresponderá ao conjunto dos recursos intangíveis: a imagem do destino turístico, o profissionalismo dos operadores, a hospitalidade da comunidade local, a atmosfera do lugar. Na realidade, não existe um só recurso que possa ser classificado numa ou outra categoria, porque cada recurso integra tanto elementos tangíveis como intangíveis e a presença simultânea dos mesmos determina a atractividade dos lugares.

De facto, assim como há recursos culturais e naturais que atraem os visitantes, pelas suas qualidades intrínsecas de excelência e pelo que invocam no imaginário do turista, também há um acolhimento que pode desempenhar uma função atractiva autónoma, em virtude da própria história e das personalidades históricas que aí habitaram. É preciso sublinhar que

7 Um recurso territorial pode ser considerado como um recurso turístico se está em condições de satisfazer as necessidades dos turistas. Tal propriedade depende das características do recurso, do perfil motivacional do turista, e por fim das acções realizadas para tornar o recurso desejável à procura turística (nível de fruição do recurso) adequando-o às necessidades desta última. 
carregar de valores emocionais a fruição dos recursos envolve um aumento do próprio nível de atractividade e de competitividade turística do lugar, que o torna único e o subtrai a avaliações comparativas - os recursos intangíveis são mais difíceis de comparar.

A atractividade tem, além disso, um valor relativo, porque desce de uma avaliação de síntese de um contexto territorial predefinido (capaz de satisfazer as necessidades da procura turística) e tende a mudar em função das características do fluxo considerado (variabilidade espacial ou geográfica) e da evolução da motivação (variabilidade temporal) (Hu, et al., 1993; Kozak, et al., 1999; Edgell, et al., 2007).

Estas características obrigam os operadores públicos e privados a uma contínua reorganização da oferta turística, a fim de a adaptar às mudanças do mercado, procurando, ao mesmo tempo, preservar a identidade territorial ${ }^{8}$ e a integridade do ambiente em relação aos imperativos do desenvolvimento sustentável (Deredge, 2006a; Anholt, 2007; Confalonieri, 2008; Mason, 2008; Hall, 2009). Com o passar do tempo, é preciso enriquecer e adaptar o quadro dos recursos competitivos, agir sobre a composição qualitativa e tipológica dos atractivos e em relação ao sistema da fruição que apresenta o mecanismo, para adaptar a oferta do território à necessidade do fluxo turístico.

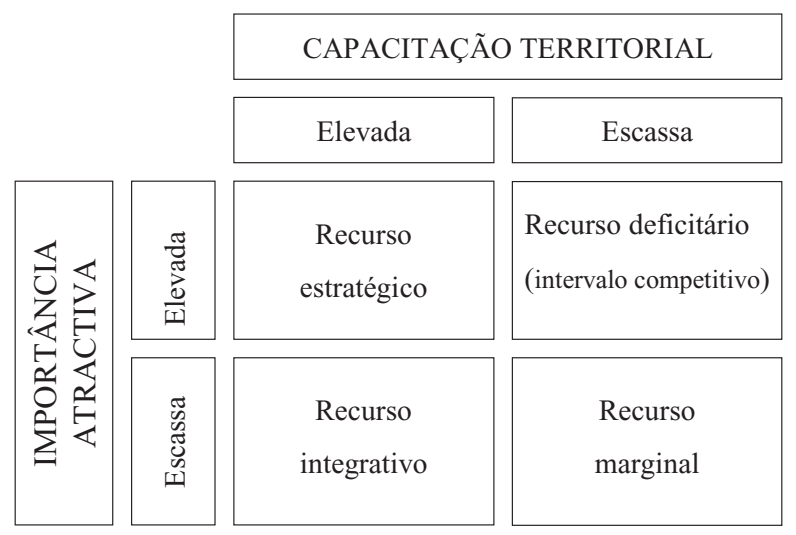

Fig. 3 - O valor estratégico dos recursos territoriais.

Fig. 3 - The strategic value of territorial resources.

A competitividade de um destino turístico reside na sua capacidade de satisfazer, de maneira mais eficaz, perante os destinos concorrentes, as necessidades dos fluxos turísti$\cos$, a preservação das próprias qualidades territoriais, contribuindo para a melhoria do bem-estar actual e futuro da comunidade local. Por um "destino de concorrência", deve-se entender uma localidade que apresenta a mesma configuração turístico-receptora ${ }^{9}$ que, por

8 Trata-se de um conjunto de recursos de vários tipos que cada comunidade organizada num território usa e gere e que constitui o potencial endógeno para o seu desenvolvimento. Não inclui apenas os recursos tangíveis resultantes do processo de territorialização do espaço, mas também os recursos intangíveis, como a capacidade empresarial, o nível cultural, o espírito de colaboração, a ética do comportamento e a sensibilidade estética. (Pollice, 2005).

9 Constitui uma componente especifica turístico-atractiva e identifica-se com a organização espacial e funcional da oferta, que está fortemente ligada às características tipológicas e motivacionais dos fluxos da procura. 
isso, pode atrair os mesmos segmentos turísticos e cuja competitividade, não pode ser medida apenas em termos de comparação da própria capacidade atractiva com a das áreas concorrentes.

A capacidade atractiva compreende, pelo menos, três tipos de factores: os actores territoriais (core resources \& attractors), em torno dos quais se estrutura a oferta turística local; o sistema de fruição e de acessibilidade turística (supporting factors \& resources), composto por um conjunto de serviços turísticos de suporte; a imagem que corresponde à percepção que o mercado turístico tem do lugar e da sua capacidade atractiva.

Cada um destes factores é inscrito num mais amplo conjunto de condições ambientais, que representa a capacitação do contexto; capacitação que contribui, indirectamente, para definir a atractividade turística do território.

A imagem turística não tem só influência nas características atractivas do lugar, mas também noutros factores territoriais, que não se podem reduzir às características da oferta turística. A competitividade, todavia, não depende apenas da capacitação em recursos disponíveis, mas também do conjunto de "habilidades" territoriais capazes de activar o potencial atractivo e de o adaptar às necessidades da procura. Estas habilidades desempenham um papel estratégico, tanto ao nível dos negócios, ou seja, da gestão dos serviços turísticos, como ao nível territorial da gestão do sistema local da oferta e na definição, realização e verificação das políticas de desenvolvimento turístico.

Não se pode esquecer que o desenvolvimento competitivo das localidades turísticas é mais frequentemente determinado pela disponibilidade de capacidades adequadas e estrategicamente orientadas, do que pela disponibilidade dos recursos (fig. 2). Estas capacidades são relevantes tanto no sector privado como no público, como se lê claramente no modelo de representação dos determinantes da competitividade turística proposto por Crouch e Ritchie (1999).

O conjunto dos recursos territoriais deve ser valorizado e desenvolvido através das suas capacidades, segundo um processo dinâmico, caracterizado por mudanças contínuas e de ciclos de reorientação.

A formação profissional dos operadores turísticos, a promoção da cultura da hospitalidade e o desenvolvimento de um eficaz modelo de destination management são variáveis críticas para o sucesso no processo de construção e de manutenção da competitividade turística do território (Minguzzi, 2006; Sciarelli, 2007; Dittman, 2009; Bornhorst, et al., 2010).

Por fim, na competitividade turística, o valor estratégico de um recurso territorial não depende apenas da importância que pode assumir no processo de atracção e de satisfação da procura, mas também da raridade da mesma (a oferta turística é frequentemente centrada em factores de singularidade e de excelência) e da sua difícil imitação noutros contextos territoriais; depende ainda, da sua efectiva utilização por parte dos sistemas de actores locais.

Não é por acaso que um dos modelos de avaliação dos recursos competitivos, o VRIO framework, se baseia na análise conjunta das três condições anteriormente referidas.

A avaliação dos recursos competitivos, como já dissemos, não pode, todavia, prescindir de uma análise comparativa das características intrínsecas da procura turística - fortemente heterogénea nos quadros da motivação, não pode senão responder a cada objectivo específico de mercado já que o nível de atractividade de um recurso depende das características psicológicas e da motivação do turista (Pollice, 2002).

Tudo isto significa que a análise competitiva deverá ser precedida de uma segmentação do mercado turístico, que pode permitir identificar segmentos representativos e suficientemente homogéneos de procura. Os critérios de segmentação mais usados são os de carácter motivacional (motivação prevalecente), geográfico, socio-demográfico e socio-económico. 
Deveria ser medido o nível de importância que o recurso pode assumir no segmento turístico considerado e a forma como a avaliação pode exprimir o grau de atractividade dos territórios em concorrência. A importância do recurso representa um elemento de ponderação, que ajuda a avaliação dos diversos atributos, para chegar a um valor de síntese do nível de competitividade absoluta.

Quadro I -Matriz de avaliação dos recursos competitivos.

Table I - Evaluation frame of competitive resources.

\begin{tabular}{|c|c|c|c|c|c|c|c|c|c|}
\hline \multirow{2}{*}{ Cod. } & \multirow{2}{*}{$\begin{array}{c}\text { Recursos } \\
\text { competitivos }\end{array}$} & \multirow{2}{*}{$\begin{array}{l}\text { Níveis de } \\
\text { importância }\end{array}$} & \multicolumn{5}{|c|}{ Avaliação comparativa* } & \multirow{2}{*}{$\begin{array}{c}\text { Valor } \\
\text { competitivo }\end{array}$} & \multirow{2}{*}{$\begin{array}{l}\text { Prioridade de } \\
\text { intervenção }\end{array}$} \\
\hline & & & 1 & 2 & 3 & 4 & 5 & & \\
\hline \multicolumn{10}{|l|}{1.} \\
\hline \multicolumn{10}{|l|}{2.} \\
\hline \multicolumn{10}{|l|}{3.} \\
\hline \multicolumn{10}{|l|}{$\cdots$} \\
\hline \multicolumn{10}{|l|}{$n$} \\
\hline $\begin{array}{l}* \text { Para } \\
4=\mathrm{m} \\
\text { excep }\end{array}$ & $\begin{array}{l}\text { valiação com } \\
\text { or; } 5=\text { muito } 1 \\
\text { no que diz res }\end{array}$ & $\begin{array}{l}\text { rativa pode se } \\
\text { lhor; esta esca } \\
\text { ito ao coeficier }\end{array}$ & & & & & & $\begin{array}{l}\text { muito pior; } \\
\text { a avaliar o nív }\end{array}$ & $\begin{array}{l}\text { pior; } 3=\text { igual; } \\
\text { e importância., }\end{array}$ \\
\hline
\end{tabular}

A avaliação dos recursos atractivos vem, assim, fundir-se com a opinião dos turistas ou melhor, dos operadores turísticos, porque estes exprimem um grau mais elevado de objectividade sobre os quadros da motivação e de experiências de fruição da procura; quando se trata de intermediários turísticos são mesmo mais capazes de desenvolver avaliações de ordem comparativa (Gearing, 1974; Formica, 2002, Dredge, 2009). A escolha da fonte informativa é ditada pela origem não objectiva da atractividade dos recursos do território que, como referido, são frequentemente caracterizados por um elevado nível de inteligibilidade. Por estas razões, a avaliação dos recursos competitivos se configura como um modelo de suporte para a tomada de decisões.

A fase fundamental desta análise competitiva é a comparação com a concorrência, entendida com o conjunto dos territórios que apresentam uma orientação turístico-receptora parecida com o contexto territorial de referência. Este tipo de comparação refere-se aos seus aspectos metodológicos aplicativos ao benchmarking territorial. ${ }^{10} \mathrm{O}$ benchmarking territorial pode ser definido como uma estratégia da comparação sistemática e contínua, que se implementa entre duas identidades territoriais, em que uma exprime um nível de excelência e outra

10 A metodologia de avaliação da competitividade turística proposta neste artigo, foi elaborada no âmbito de um projecto de investigação mais amplo sobre a valorização dos sítios arqueológicos da bacia do Mediterrâneo, financiado pelo Ministero dell'Istruzione, dell'Università e della Ricerca Scientifica della Repubblica Italiana (MIUR - Ministério da Educação, da Universidade e da Investigação). O projecto, ainda em desenvolvimento, prevê a aplicação deste modelo nas localidade de destino turístico que incluem na própria oferta turística um sitio arqueológico de nível internacional, e tem como objectivo a comparação dos diversos níveis de atractividade dos lugares, para determinar as melhores estratégias de desenvolvimento sustentável da oferta turística. 
um modelo competitivo de referência. O benchmarking territorial utiliza também terminologias e modelos conceptuais da economia da empresa e pode ser considerado como uma evolução do método de comparação da evolução geográfica; é uma aplicação especial, nalguns aspectos inovadora, uma aproximação cognitiva orientada para a investigação das causas das diferenças territoriais.

A comparação é orientada para delinear, em referência a um contexto específico local, as estratégias de desenvolvimento segundo uma lógica competitiva que considera o território como um sistema integrado de recursos em concorrência, à escala global ou regional, com outras localidades caracterizadas por uma configuração sistémica semelhante (o quadro dos recursos). A fase central deste método de comparação é a determinação dos benefícios competitivos em que se baseia a excelência do main competitor. Nesta interpretação, os sistemas turísticos locais representam o espaço de aplicação desta técnica. Tais contextos territoriais, sendo realidades homogéneas, integradas nas várias funções e geograficamente bem circunscritas, prestam-se de facto a estas comparações. A comparação, nestes casos, foca-se sobre os factores de atracção simples - elementos fundamentais do sistema local de oferta, na organização do espaço turístico e na interacção que se gera entre as dimensões receptora e a territorial.

Do ponto de vista da aplicação, o método desenvolve-se através do estudo sistemático das diferenças competitivas e das suas causas, segundo um modelo processual cíclico, no qual cada fase surge em consequência de um único percurso de pesquisa e tem um valor cognitivo específico e autónomo.

Uma vez identificadas as diferenças, poderá avançar-se na definição dos objectivos do sistema e na elaboração das estratégias e adaptá-los, no respeito pelas especificidades do contexto territorial e na convicção de que a reprodução do modelo de desenvolvimento oferecido de concorrente piloto seja, de facto, limitada, senão nula, sendo importante a comparação na fase da definição do crescimento competitivo do contexto local. O risco, de facto, está no uso do benchmarking como uma estéril estratégia de emulação, que pretende reproduzir os percursos de desenvolvimento experimentados noutros locais, sem verificar a sua compatibilidade ou a contextualização.

Para além das dúvidas referidas, os métodos descritos têm o mérito de fornecer um eficaz enquadramento competitivo para a elaboração das estratégias de desenvolvimento local e, em particular, de alcançar os seguintes objectivos específicos: definir a configuração turístico-receptiva actual (que somos?) do destino turístico; identificar os destinos concorrentes; medir as vantagens e desvantagens competitivas do sistema turístico local, em relação às concorrentes e aos segmentos da procura, antever como o território pode ser em termos turísticos e atractivos (que poderemos ser), ou seja, a configuração turística objectiva e, por último, motivar as escolhas estratégicas tomadas pelos operadores (que queremos ser). A avaliação do potencial competitivo é a condição fundamental na identificação das estratégias de desenvolvimento turístico do território (fig. 1).

\section{A POSIÇÃO COMPETITIVA E AS ESTRATÉGIAS DE DESENVOLVIMENTO DA DOTAÇÃO ATRACTIVA}

Definir a configuração turística e atractiva do território e, sobretudo, intervir nesta última, pode assumir uma forma concreta no plano da oferta e da imagem do mercado, quer dizer, promover a posição competitiva do território no cenário turístico nacional e internacional. A posição competitiva -termos utilizados na economia das empresas e nem sempre usa- 
dos de maneira correcta em relação à realidade territorial - apresenta um elevado conteúdo estratégico, que pode assumir um valor concorrencial relativamente à participação e ao envolvimento dos actores locais; a posição é parte de uma estratégia de reorientação mais ampla do sistema local de oferta e precisa de uma partilha dos objectivos e de coerência sistémica das acções empreendidas pelos actores locais.

Para promover o envolvimento dos actores, podemos utilizar diversos modelos de estudo; um deles, que cremos mais eficaz, é o l'European Awareness Workshop Scenario (EAWS). No passado foi utilizado para procurar soluções para problemas ambientais; metodologicamente, propõe-se estimular a participação democrática nas escolhas para melhorar o território e promover a passagem de modelos de desenvolvimento sustentável partilhados e baseados no uso mais equilibrado dos recursos (Martilla, et al., 1997; Sicca, 2000; Valdani, et al., 2000; Di Meo, 2002). No plano operacional, concretiza-se na activação de um fórum de discussão com uma representação qualificada de stakeholders locais.

A procura turística apresenta-se como uma realidade fortemente diferenciada, tanto no plano das motivações como no sócio-económico. As estratégias de posição competitivas não podem senão desenvolver-se segundo dois níveis distintos: por um lado, a análise estratégica dos mercados objectivos, através da qual é possível distinguir os tipos de turismo que o território pode suportar em termos competitivos; por outro, a definição da posição que dentro do mercado-objectivo o território pode assumir, considerando a própria posição actual e a dos territórios concorrentes. Tudo isto se baseia em indicações que o território pode elaborar e seguir, no âmbito de uma estratégia competitiva sobre a própria configuração turístico-atractiva.

No primeiro nível de análise identificam previamente os tipos de turismo que o território pode atrair, em função das suas próprias características turístico-actractivas, avaliando a sua importância em relação ao mercado-objectivo (valor de mercado, tendências evolutivas) e o nível de competitividade actual e em perspectiva do território - este último medido com base nos resultados da análise comparativa dos recursos atractivos.

A escolha dos mercados-objectivos em que se podem concentrar os esforços competitivos dos actores locais pode ser efectuada através da utilização de uma matriz de orientação estratégica, como se refere na figura 3.

O território deverá investir nos mercados (tipos de turismos) que, em função do próprio valor económico ou das tendências de facto (ex. tipos de turismos que atravessam uma fase de forte expansão) apresentam um elevado nível de atractividade e onde a própria oferta turística apresenta fortes níveis de competitividade. Ao contrário, onde o nível de competitividade for baixo, também o mercado-objectivo será pouco atractivo, sendo preciso desencorajar os retractivos fluxos turísticos. Onde se observar uma situação intermédia (na figura 3, com ausência de avaliação), será preciso avaliar as tendências evolutivas do mercado-objectivo em termos de atractividade/competitividade e avaliar as orientações estratégicas dos actores locais. Se, por exemplo, se julgar que o território pode reforçar a própria posição competitiva no mercado-objectivo e aumentar a atractividade relativa, pode-se optar por uma estratégia de investimentos competitivos; caso contrário, será mais oportuno dirigir-se para outros mercados. As mesmas considerações podem desenvolver-se para aqueles mercados-objectivos que assumam um papel estratégico para a imagem do território, ou possam desenvolver relações sinergéticas com outros mercados de interesse.

A análise até agora descrita pode ter também como referência os agrupamentos (clusters) geográficos, com distinção dos segmentos mais representativos em termos de atractividade/competitividade. Neste caso, a matriz fornece indicações estratégicas sobre os clusters geográficos onde se devem concentrar os esforços competitivos (fig. 4). 


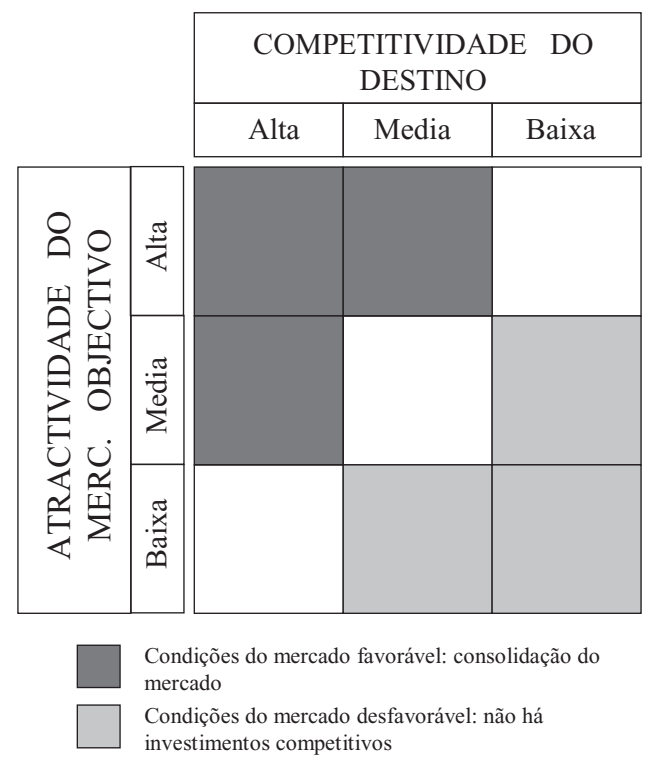

Fig. 4 - Matriz de orientação estratégica.

Fig. 4 - Strategic orientation matrix.

Uma vez diferenciados os mercados-objectivos, pode-se avançar na definição da posição competitiva de cada mercado específico, e na generalidade, do mercado interno turístico. Distinguir a posição de um destino turístico quer dizer, essencialmente, definir as características específicas que deve assumir a oferta local em relação à oferta dos territórios concorrentes; todavia, elas devem ser diferenciadas logo que possível, numa lógica de eficácia, sobretudo quando há poucos recursos de organização e de promoção. Uma posição eclética, ou seja, longe da dos principais concorrentes, tem a própria justificação na vontade de orientação para uma componente do mercado específica (segmento turístico), em função da sua caracterização; constitui uma procura específica que o território pode satisfazer com mais eficácia face aos concorrentes, em virtude da própria capacidade atractiva. A importância de uma estratégia de posição vai, por isso, depender do nível do segmento do mercado-objectivo: num mercado caracterizado por uma procura homogénea e indiferenciada a posição tem uma importância relativa. Tal como para a escolha do mercado-objectivo, também a distinção da orientação estratégica não pode ser independente de avaliações de carácter económico; claro que estas últimas devem inserir-se num modelo de decisão que dê prioridade aos critérios de sustentabilidade ambiental e de coerência territorial. Os critérios económicos, utilizados para a selecção dos segmentos-objectivos são, essencialmente, a capacidade de despesa do segmento e a duração média da estadia. Deve ter-se em consideração que a despesa média de um dia tende a diminuir com o aumento do período da estadia, sendo os segmentos mais interessantes (priority markets) caracterizados por um alto nível de despesa e uma estadia limitada - o que deve ser problematizado, se as estratégias dos operadores turísticos têm por objectivo prolongar a estadia dos turistas (fig. 5). 


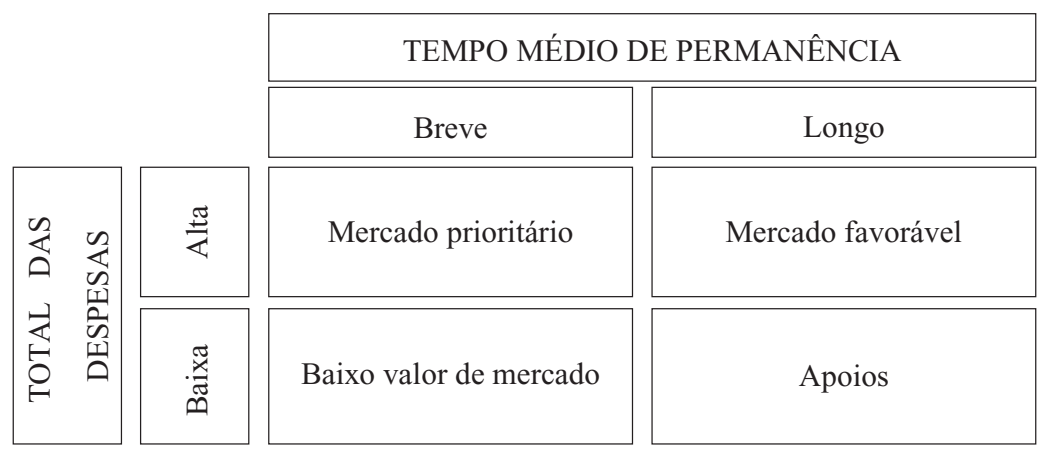

Fig. 5 - Critérios economicistas para a selecção dos segmentos turísticos.

Fig. 5 -Economic criteria for the selection of tourist segments.

Fonte: Lee, Morrison, O’Leary, 2006.

A construção de um mapa de posição, dentro do qual se vai inscrever o posicionamento dos concorrentes, é uma operação que parte da distinção de dois conjuntos de características atractivas e que as investigações directas têm demonstrado influenciar as decisões dos turistas, ou pelo menos construir critérios de selecção do destino turístico. Em Itália, por exemplo, está-se perante instrumentos de suporte das decisões estratégicas que sofrem limitações. Existem alguns modelos estatístico-matemáticos que suportam tanto a fase de distinção das variáveis, como as representações gráficas da posição competitiva,as quais permitem dar um fundamento científico a este método de análise, ainda que o valor normativo destes modelos seja limitado.

O mapa do posicionamento fornece indicações sobre a posição que actualmente o território ocupa dentro do mercado turístico de referência e não a sua posição real, que se poderia deduzir de uma avaliação objectiva dos potenciais atractivos; resulta das percepções e da experiência da procura (a posição percebida) e do posicionamento objectivo, ou seja, que seria desejável assumir em função das oportunidades oferecidas ao mercado e a sua especificidade territorial. Muitos mapas de posicionamento propostos na bibliografia científica sobre o tema (Cracolici, et al., 2009; Gallarza, et al., 2002; Meliàn-Gonzàles et al., 2003) apontam, na realidade, para fenómenos diferentes, como a diversa configuração atractiva dos territórios turísticos ou da imagem do mercado.

Um dos modelos mais interessantes é o desenvolvido por Echtner e Ritchie no início dos anos noventa, para análise das imagens dos destinos turísticos. O método é muito interessante, sobretudo tendo em consideração os desenvolvidos até hoje - porque fornece um esquema do posicionamento dos factores atractivos individuais. As características específicas da oferta local são analisadas e catalogadas através da utilização de um conjunto de três critérios distintos: o nível de standardização do factor atractivo; a origem funcional (por exemplo, instalações) ou psicológica (por exemplo, a hospitalidade) do factor atractivo; a percepção, real ou evocativa, do factor atractivo (fig. 6).

Igualmente interessante é a tentativa de posicionar os destinos turísticos com base nos aspectos fundamentais da orientação atractiva: por um lado, o nível de especialização atrac- 
tiva e, por outro, o nível de territorialização da oferta (Emanuel, 1994; Jamal, et al., 1995; Reed, 1997; Calver-Cortes, et al., 2007; Hall, 2008). Trata-se, de facto, de dois critérios de diferenciação das configurações atractivas que assumem uma importância estratégica no plano do posicionamento do mercado e das componentes turísticas. Em termos da especialização atractiva, os destinos turísticos tendem a ser preparados longe de um continum ideal: do especializado sobre um único mercado objectivo, para um com uma configuração turística aberta, capaz de atrair tipos diversos de turismo, caracterizados por quadros motivacionais que têm por resultado modelos de fruição diversos, mas também compatíveis entre si (a compatibilidade é uma condição inelutável, porque não se produzem contrastes no uso dos recursos atractivos e das instalações). No actual cenário competitivo, a especialização atractiva, tanto de origem tipológica quanto de origem geográfica, solicita a adopção de uma estratégia de excelência: procurar uma configuração da oferta que responda, com pontualidade e eficiência, à procura de um objectivo, de forma que ele possa constituir o lugar ideal para satisfazer as necessidades turísticas. Obviamente, uma tal opção estratégica desenvolve-se de forma responsável apenas naqueles territórios que apresentam características de excelência nalguns atractivos específicos. Particularmente significativos são aqueles territórios em que é preciso concentrar os esforços competitivos, ou que tenham desenvolvido uma capacidade atractiva consolidada no referido objectivo, adquirindo uma imagem fortemente orientada.

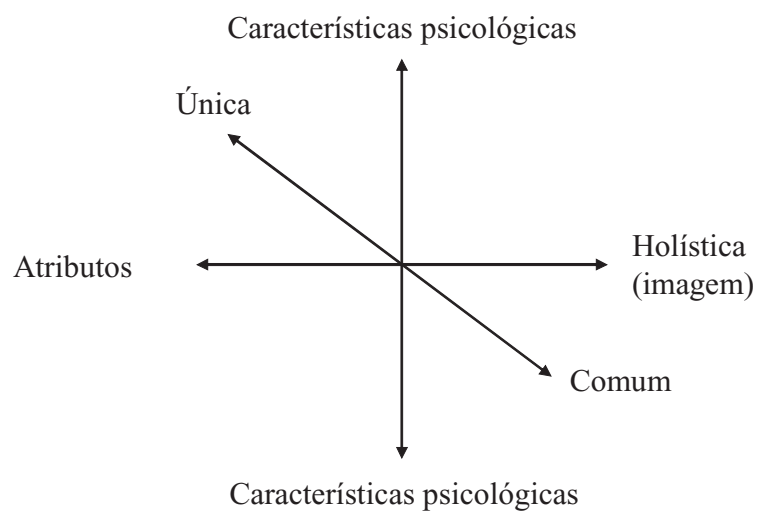

Fig. 6 - A componente da imagem do destino turístico (Echtner e Ritchie, 1993).

Fig. 6-The image component of the tourist destination (Echtner e Ritchie, 1993).

A diversificação, ao contrário, baseia-se na pesquisa de uma configuração atractiva que seja capaz de captar diversos fluxos turísticos, em termos geográficos e tipológicos, ou motivacionais. A diversificação torna-se "naturalmente" um objectivo a perseguir sempre que existam condições territoriais para desenvolver uma capacidade atractiva de tipo "pluritemático". Todavia existem muitas excepções que atestam como se pode prescindir do processo de diversificação atractiva. A diversificação como estratégia de desenvolvimento turístico requer um grande esforço de organização, em função da complexidade tipológica dos serviços que se devem activar, implementar para as necessidades do objectivo. Igualmente importante nesta óptica, é o papel de coordenação do sistema; é adequado desenvolver uma oferta de 
tipo modular que pode ser re-organizada pela procura, com base das necessidades do turista único. Para responder de maneira mais eficaz e personalizada às necessidades do turista, sem bloquear a estrutura com novos custos, é preciso ter um sistema flexível e deixar ao turista a tarefa de recompor como um puzzle a oferta local.

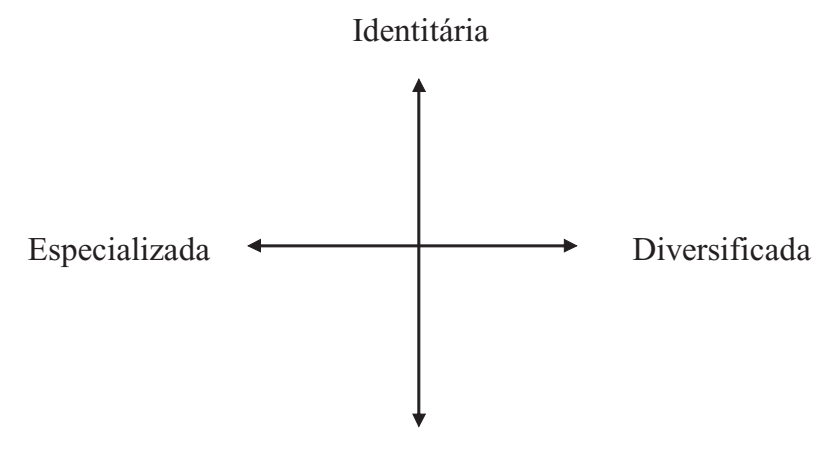

Homologada

Fig. 7 - A orientação competitiva da oferta turística local.

Fig. 7 - Competitive orientation of the local tourism.

No plano da especificidade atractiva, podem-se encontrar, igualmente, situações igualmente diversas, com sistemas turísticos que apresentam uma oferta homóloga da dos próprios concorrentes e caracterizados por um forte marco identitário e outra que, ao contrário, concentram a oferta sobre os traços de diferenciação que caracterizam o território. A necessidade de relacionar os segmentos transnacionais da procura obriga as localidades turísticas a adequarem as necessidades e as expectativas da procura internacional; mas esta estratégia aparece mais correcta no perfil da adequação da qualidade e da tipologia de alguns serviços turísticos - por exemplo, pode-se elogiar o standard qualitativo das instalações turísticas ou de transporte, mas esta oferta turística pode estar a ser efectuada em detrimento daquelas que são as reais vocações turísticas do território. As últimas tendências evolutivas da procura mostram que a ideia de férias como descanso deve ser gradualmente integrada ou, noutros casos, substituída pela de viagem, como uma experiência exótica capaz de emocionar e de enriquecer o indivíduo do ponto de vista cultural; uma alteração que volta a atribuir centralidade às características culturais do lugar e à capacidade de construir em redor deles uma oferta integrada e coerente. A mesma intensificação do quadro competitivo, a sugerir a adopção de uma estratégia de diferenciação da oferta, torna o território reconhecível e com uma atractividade específica própria.

Uma vez mais, a importância estratégica da análise competitiva e da capacidade de leitura e de interpretação das vocações territoriais leva a afirmar que a via possível para o desenvolvimento do turismo sustentável ao nível local, é aquela que vê no território a fonte fundamental das vantagens competitivas que podem determinar o êxito do destino turístico e a capacidade de competir para melhorar o bem-estar actual e futuro da comunidade local. 


\section{CONSIDERAÇÕES FINAIS}

As políticas de turismo ao nível local são frequentemente elaboradas a partir das aspirações do território, e não tanto sobre as suas reais vocações; tudo isto porque na base das estratégias de desenvolvimento não há uma análise competitiva do território e das suas potencialidades turísticas, mas a tentativa de apresentar modelos exógenos de desenvolvimento, frequentemente sem se pesquisar uma possível contextualização. Ao contrário, como tentámos demonstrar, a análise dos recursos competitivos assume uma importância central no processo de elaboração das políticas de turismo, porque permite ler e interpretar as vocações territoriais, no sentido das dinâmicas evolutivas do mercado e do posicionamento competitivo dos territórios em concorrência. Uma aproximação, de tipo resource-based, pode atribuir uma prioridade estratégica à capacitação atractiva do território, permite promover formas de desenvolvimento sustentável, porque conduz à realização de uma configuração que se centra nas qualidades das paisagens, naturais e culturais do território, de forma a preservar os valores identitários e os equilíbrios ambientais. Uma configuração atractiva sustentável é aquela que leva a minimizar o impacte ambiental das actividades turísticas, face às vocações turísticas do lugar. Existe, de facto, uma forte relação entre atractividade e sustentabilidade que, estranhamente, escapa quer aos operadores turísticos, quer aos organismos de ordenamento do território; uma relação que se releva quer no plano de atracão dos fluxos turísticos, quer no plano da organização da oferta. No primeiro, a atractividade representa, de facto, uns dos aspectos mais importantes e selectivos da procura. Um desenvolvimento selectivo da atractividade - e dos recursos competitivos - permite atrair segmentos compatíveis e promover uma fruição sustentável do território. Uma configuração atractiva ligada a uma estratégia clara e partilhada de um sistema, pode induzir a oferta, através da emulação competitiva e do imprinting territorial, mecanismos de convergência que podem melhorar as performances ambientais.

O desenvolvimento de um modelo sustentável de turismo baseia-se na capacidade de construir uma base de recursos competitivos do território, uma oferta coerente e integrada, capaz de responder às necessidades dos fluxos turísticos atraídos ou potencialmente a atrair. O pressuposto desta aproximação estratégica, é a aquisição de uma visão mais ampla do conceito de concorrência turística que não pode ser reduzido à presença dos actores ambientais e culturais, nem à simples disponibilidade de instalações adequadas. Os recursos competitivos são todos aqueles elementos territoriais (tangíveis ou intangíveis) que, de maneira directa ou indirecta, contribuem para satisfazer as necessidades, ou criar as condições para que elas possam ser adequadamente satisfeitas. A complexidade dos recursos competitivos e a heterogeneidade dos actores envolvidos mostra que a concorrência é o resultado de uma interacção sistémica de matriz territorial e que quanto maior for o desenvolvimento de um mecanismo de coordenação de base local, mais coerentes e eficazes na concorrência serão as estratégias do desenvolvimento turístico à mesma escala.

\section{AGRADECIMENTOS}

Os autores agradecem as sugestões dos revisores científicos, que ajudaram a melhorar a versão final deste texto. 


\section{BIBLIOGRAFIA}

Anholt S (2007) L'identità competitiva. Il branding di nazioni, città, regioni. Egea, Milano.

Berardi S (2007) Principi economici ed ecologici per la pianificazione di uno sviluppo turistico sostenibile. Franco Angeli Ed., Milano.

Bornhorst T, Brent Ritchie J R, Lorn Sheehan (2010) Determinants of tourism success for DMOs \& destinations: An empirical examination of stakeholders perspectives. Tourism Management, 31(5): 572-589.

Buhalis D (2000) Marketing the competitive destination of the future. Tourism Management, 21(1): 97-116.

Burns P M (2004) Tourism planning: a third way? Annals of Tourism Research, 31(1): 24-43.

Caroli G M (2006) Il marketing territoriale. Strategie per la competitività sostenibile del territorio. Franco Angeli ed., Milano.

Claver-Cortés E, Molina-Azorı J F, Pereira-Moliner $\mathrm{J}$ (2007) Competitiveness in mass tourism. Annals of Tourism Research, 34(3): 727-745.

Confalonieri M (2008) Il turismo sostenibile Giappichelli ed., Torino.

Cracolici M F, Nijkamp P (2009) The attractiveness and competitiveness of tourist destinations: a study of Southern Italian regions, Tourism Management, 30(3): 336-344.

Crouch G I, Ritchie J R B (1999) Tourism, competitiveness, and societal prosperity. Journal of Business Research, 44(3): 137-152.

Dall'Ara G (2006) Come progettare un piano di sviluppo turistico territoriale Normativa, marketing, casi di eccellenza. Halley, Matelica (Mc).

Dittmann M (2009) Community based tourism modern destination management. Paperback, Print On Demand.

Di Meo A (2002) Il marketing dell'ambiente e della cultura per lo sviluppo tuiristico del territorio. Lupetti, Milano.

Dredge D (2009) Place change and tourism development conflict: evaluating public interest. Tourism Management, 31(1): 104-112.

Dredge D (2006a) Networks, conflict and collaborative communities. Journal of Sustainable Tourism, 14(6): 562-581.

Dredge D (2006b) Policy networks and the local organisation of tourism. Tourism Management, 27(2): 269-280.
Dredge D, Jenkins J (2007) Tourism planning and policy. John Wiley, Brisbane.

Edgell D, Del Mastro Allen M, Smith G, Swanson (2007) Tourism policy and planning: yesterday, today and tomorrow. Butterworth-Heinemann, Oxford.

Ejarque J (2003) La destinazione turistica di successo. Hoepli, Milano.

Enright M J, Newton J (2004a) Tourism destination competitiveness: a quantitative approach. Tourism Management, 25(6): 777-788.

Enright M J, Newton J (2004b) Tourism destination competitiveness: a quantitative approach. Tourism Management, 25 (3): 777-788.

Emanuel C (1994) Località turistiche montane e milieu locale. Esami e riflessioni su alcuni modelli analitici. Rivista Geografica Italiana, 1: $1-20$.

Echtner E, Ritchie J R B (1993) The mesasurement of destination image: an empirical assessment. Journal of Travel Research, 2: 213-230.

Franch M (2010) Il Marketing delle destinazioni turistiche McGraw-Hill, Milano.

Gallarza M G, Saura I G, Garcia H C (2002) Destination image towards a conceptual framework. Annals of Tourism Research, 29 (1): 56-72.

Gearing C E, Swart W W, Var T (1974) Establishing a measure of touristic attractiveness. Journal of Travel Research, 12(1): 1-8.

Hall C M (2009) Undertanding and managing tourism impacts: an integrated approach. Routledge - Taylor \& Francis Group, London.

Hall C M (2008) Tourism planning: policies, processes and relantionship. Prentice Hall, Harlow.

Hall C M (2007) Tourism and regional competitiveness. Developments in Tourism Research: 217-230.

Jamal T B, Getz D (1995) Collaboration theory and community tourism planning. Annals of Tourism Research, 22(1): 186-204.

Formica S (2002) Measuring destination attractiveness: a proposed framework. Journal of American Academy of Business, 1(2): 350-355 .

Hu Y Z, Ritchie J R B (1993) Measuring destination attractiveness. A contextual approach. Journal of Travel Research, 32(2): 25-35. 
Kozak M Rimmington M (1999) Measuring tourist destination competitiveness: conceptual considerations and empirical findings. International Journal of Hospitality Management, 18(3): 273-284.

Lee G, Morrison A M, O’Leary J T (2006) The economic value portfolio matrix: a target market selection tool for destination marketing organization. Tourism Management, 27(2): 576-588.

Lozato Giotart J P, Balfet M (2009) Progettazione e gestione dei sistemi turistici. Hoepli, Milano.

Martilla J A, James J C (1977) Importance-performance analysis. Journal of Marketing, 1: 77-79.

Mason P (2008) Tourism impacts, planning and management. Butterworth-Heinemann, Oxford.

Melián-Gonzáles A, García-Falcón J M (2003) Competitive potential of tourism in destinations. Annals of Tourism Research, 30(3): 720-740.

Micozzi G (2006) Marketing della cultura e del territorio. Franco Angeli, Milano.

Minca C (1996) Spazi effimeri. Cedam, Padova.

Minguzzi A (2006) Destination competitiveness and the role of destination management organization (DMO): an italian experience. In Lazzaretti L, Petrillo C S (eds) Tourism local systems and networking. Elsevier: 197-208.

Oh H (2001) Revisiting importance-performance analysis. Tourism Management, 22(6): 617-627.
Pollice F (2005) Il ruolo dell'identità territoriale nei processi di sviluppo locale. Bollettino della Società Geografica Italiana, X(1): 75-92.

Pollice F (2002) Territori del turismo. Franco Angeli, Milano.

Pollice F, Spagnuolo F (2009a) Attrattività e sostenibilità: una lettura congiunta per lo sviluppo turistico locale. Turismo e Psicologia. Rivista interdisciplinare di studi, ricerche e formazione, 2: 54-76.

Pollice F, Spagnuolo F (2009b) Branding, identità e competitività. Geotema, 37: 49-56.

Reed M G (1997) Power relations and community-based tourism planning. Annals of Tourism Research, 24(3): 566-591.

Ritchie J R B, Crouch G I (2000) The competitive destination: a sustainability perspective. Tourism Management, 21(1): 1-7.

Sciarelli S (2007) Il management dei sistemi turistici locali. Giappichelli, Torino.

Sicca L (2000) Il ruolo del marketing nello sviluppo turistico. In Bellini N (ed.) Il marketing territoriale. Sfide per l'Italia nella nuova economia Franco Angeli, Milano, 38-129.

Società Geografica Italiana (2007) Turismo e territorio. L'Italia in competizione. Roma.

Valdani E, Ancarini F (2000) Strategie di marketing del territorio. Egea, Milano. 